\title{
Erratum to: Small Science: Infants and Toddlers Experiencing Science in Everyday Family Life
}

\author{
Shukla Sikder ${ }^{1} \cdot$ Marilyn Fleer $^{1}$
}

Published online: 25 August 2016

(C) Springer Science+Business Media Dordrecht 2016

\section{Erratum to: Research in Science Education (2015) 45:445-464 \\ DOI 10.1007/s11165-014-9431-0}

The authors would like to clarify that in the article 'Small science: Infants and toddlers experiencing science in everyday family life' published with the journal Research in Science Education, 45 (3), pp. 445-464, the one focus family (Aarjaw family) has been withdrawn from the study. Therefore, the number of participants should be three (instead of four) and total hours of video data $30 \mathrm{~h}$ (instead of 51), collected over 1 year (instead of two). The substitute transcript (the vignette and the interpretation of the vignette) is added here below. In the 'Findings' section, the vignette and the interpretation of the vignette have been replaced only and please note that no conceptual change or content change of any significance has been made in the other parts of the 'Findings' section.

\section{The Vignette}

Activity settings: Preparing different shapes with playdough through a playful context

Date: 17 September 2012, Location-Singapore,

Participants: Jhuma (Jhumki's mother), Jhumki (23 months), Jhumki's teddy bears. Total video length: $50 \mathrm{~min}$ and field notes on the day

Small science - press hard, push, roll and change of state of matter (dough becomes elephant, finger, doll, duck, cake)-force

The online version of the original article can be found at http://dx.doi.org/10.1007/s11165-014-9431-0.

Shukla Sikder

shukla.sikder@monash.edu

1 Department of Early Childhood Education, Monash University, Building A, McMahons Road, PO Box 527, Frankston, VIC 3199, Australia 
Jhuma has one paper and two playdough containers on the floor. Jhumki looks at the containers, sits on the floor, and tries to open the containers. Jhuma is busy with something. R1 sits beside Jhumki and opens the lid of the containers. Jhuma brings some different shapes, different coloured dough, and one pressing toy. Jhuma takes some play dough and starts to do rolling and says to Jhuma, "Please follow me".

Jhuma: Jhumki, roll by turning around your hand and make a dough ball.

Jhumki follows her mother and rolls out the dough. Jhuma takes the pressing toy and presses the dough to make it flat.

Jhuma: Jhumki, see what I am doing (2/3 times)? I am pressing the dough.

Jhuma: Press, press, press.

Jhumki goes to R1 and observes her mother's activity through the video camera. Jhuma makes different shapes by using shapes such as an Elephant.

Jhuma: Elephant, wow! Very nice.

Jhumki goes back to the play context after some time. Jhumki brings all of her teddy bears to play with her. Jhuma helps her to set the bears in the play context.

Jhuma: Press the doll shape cutter (2/3 times) on the dough and make a doll.

Jhuma holds Jhumki's hand and helps her to press hard.

Jhuma: Jhumki, press/push a duck biscuit cutter (3/4 times) on the dough.

Jhumki pushes the duck shaped biscuit cutter then Jhuma helps her to push hard and take out the duck shape from the cutter. Jhuma makes sounds like quack quack. Jhumki also says, "quack, quack".

Jhuma again takes the dough and makes Jhumki's finger shape by pressing her finger into dough. R1 helps her to do so.

Then Jhuma starts to make a birthday cake with the dough as Jhumki's birthday is coming soon.

Jhuma makes two layers of the cake and starts to sing "Happy birthday". Jhuma prepares candles and puts them on the cake and Jhumki does the same thing. Jhumki wants one birthday hat and her mum makes one with dough. Then she pretends to cut the cake with the plastic toy knife by pressing the knife and her mum sings the song. Jhumki also sings the song.

They are making another shape. Jhuma holds Jhumki's hand and supports Jhuma to press correctly into the dough. Jhumki does it by herself.

Jhuma: Good, well done.

They make another cake and Jhumki helps her mum to cut the cake. Jhuma also mentions the dough's colour, such as red, yellow and green, throughout the play moment. Jhumki repeats the colour name.

Then Jhumki takes the dough and presses with the one finger cutter and presses by herself and make a finger shape. Jhuma and R1 clap hands and encourage her to do the same.

Jhuma tells her the names of the shapes. Jhumki touches all the shapes and tries to follow Jhuma by saying the names. Jhuma repeats the whole process three/four times (roll, press hard, push the cutter, turn the dough into a shape) and explains the process every time to the child. Jhumki follows the steps at all times, doing exactly what her mother does. R1 also participates as a passive play partner as required. 


\section{Interpretation of the Vignette}

The play event is derived from Jhumki's regular play activities in the home. She appeared motivated to engage in the play moment. Jhumki was familiar with the materials and the process/steps of the event. Play is integrated into everyday family practises (Elkonin 2005) as they celebrate a birthday in the play context. The context was the combination of everyday activities (birthday moment) and using play materials to make different shapes, such as a cake, elephant and doll. Elkonin (2005) has argued that children want to act like adults. This was evident when Jhumki acted like her mother, pressing out the dough in exactly the same way as she did. Under the age of three, play is serious business for children (Vygotsky 1966). Jhumki took the play activity very seriously and concentrated on the preparation of the different shapes.

Jhumki learned small science concepts such as to press hard, to push, to roll and to turn the play dough into shapes (e.g., as a doll or duck) through her mother's simple scientific narration to accompany these movements and moments. Jhumki's play motive in this event, and her interest to make different shapes, had a serious purpose (Vygotsky 1966). The language of push, press hard, and roll, as symbolic of actions of force, represent moments of small science that occur during positive and engaged playful interaction at home. At this stage, we can say the academic concept of force will not be learned completely. However, it will become incrementally understood through the learning of small science concepts such as push, press hard and roll in everyday life. As Vygotsky (1987) stated, it is impossible for a child to immediately learn scientific concepts in a final form; rather, the child needs to experience the processes of the concept in everyday situations before conceptual development is fully established. The concept of small science helps name this incremental process that is so relevant for infants and toddlers experiencing science concepts in everyday life. Jhumki's everyday play activities through this event helped her to experience these science concepts as small science moments.

Also, Jhumki understands how dough changes shape through the process of pushing, pressing, and rolling. This one example of everyday science play illustrates how everyday situations are not only filled with small science moments but that families give these moments scientific meaning through how they narrate these events. In the case of Jhuma and Jhumki (see also Table 2 in the original article), it is evident that small science moments were being narrated regularly in everyday playful situations. 